\title{
TRATAMENTO COM CLORETO DE CÁLCIO NA PÓS-COLHEITA RETARDA O DESVERDECIMENTO E A PERDA DE FIRMEZA DO MAMÃO UENF/CALIMANO1 ${ }^{1}$
}

\author{
WILLIAN BATISTA SILVA², GLÁUCIA MICHELLE COSME SILVA ${ }^{3}$, LIGIA RENATA DA SILVA ${ }^{3}$ \\ WALTER RUGGERI WALDMAN ${ }^{4}$, JURANDI GONÇALVES DE OLIVEIRA ${ }^{5}$
}

RESUMO - Com o objetivo de prolongar o período de conservação e manter a qualidade do mamão UENF/ Caliman01, foram testadas diferentes concentrações de $\mathrm{CaCl}_{2}$ aplicadas por infiltração a vácuo. Os frutos foram separados em seis lotes, o controle (sem tratamento) e os tratamentos que receberam a aplicação de $\mathrm{CaCl}_{2}$ a $0 \%, 2 \%, 4 \%, 6 \%$ e $8 \% \mathrm{CaCl}_{2}(\mathrm{p} / \mathrm{v})$ por imersão sob vácuo, por 3 minutos, a $50 \mathrm{kPa}$ de tensão, com posterior análises da perda de massa fresca, firmeza do fruto, firmeza do mesocarpo, ângulo de cor hue, teores de sólidos solúveis (SS), acidez titulável (AT), ácido ascórbico, açúcares solúveis totais e razão SS/AT. Os tratamentos com cálcio não interferiram na perda de massa que, de modo geral, incrementou ao longo do tempo, porém os frutos permaneceram verdes e firmes por mais tempo quando tratados com $\mathrm{CaCl}_{2} 6 \%$ e $8 \%$ $(\mathrm{p} / \mathrm{v})$. $\mathrm{O}$ uso do $\mathrm{CaCl}_{2}$ não interferiu nas características químicas do fruto, tais como sólidos solúveis, acidez titulável e razão SS/AT, porém diminuiu a síntese de ácido ascórbico e a degradação dos açúcares solúveis. Termo para indexação: Carica papaya, qualidade, açúcares solúveis, textura de polpa, coloração de casca, $\mathrm{CaCl}_{2}$.

\section{TREATMENT WITH CALCIUM CHLORIDE AT POSTHARVEST DELAYS THE DEGREENING AND LOSS OF FIRMNESS OF PAPAYA/UENF/CALIMAN01}

\begin{abstract}
In order to prolong the shelf life and maintain the quality of Papaya/UENF/Caliman01, different concentrations of $\mathrm{CaCl}_{2}$ applied by vacuum infiltration were tested. The fruit were separated into six groups: control (no treatment) and treatments with $\mathrm{CaCl}_{2}$ at $0 \%, 2 \%, 4 \%, 6 \%$, and $8 \% \mathrm{CaCl}_{2}(\mathrm{w} / \mathrm{v})$, applied by immersion under vacuum during $3 \mathrm{~min}$ at $50 \mathrm{kPa}$ tension. Further analysis was then performed with respect to weight loss, fruit firmness, mesocarp firmness, hue angle color, soluble solids (SS), titratable acidity (TA), ascorbic acid, total sugars, and the SS/TA ratio. The calcium treatment did not affect the weight loss, which generally increased over time. However, the fruit remained green and firm longer when treated with $\mathrm{CaCl}_{2}$ at $6 \%$ and $8 \%(\mathrm{w} / \mathrm{v})$. The use of $\mathrm{CaCl}_{2}$ did not affect chemical fruit characteristics such as soluble solids, titratable acidity, and SS/TA ratio, but did decrease the synthesis of ascorbic acid and the degradation of soluble sugars.
\end{abstract}

Index terms: Carica papaya, quality, soluble sugar, texture of the pulp, skin color, $\mathrm{CaCl}_{2}$.

\footnotetext{
'(Trabalho 158-14). Recebido em: 09-05-2014. Aceito para publicação em: 23-09-2014.

${ }^{2}$ Mestrandos pela Universidade Estadual do Norte Fluminense - Darcy Ribeiro, Campos dos Goytacazes - RJ, Avenida Alberto Lamego, 2000 - Parque Califórnia. CEP: 28013-602. E-mail: williambatistadasilva@gmail.com; ligiarenata@agronoma.eng.br ${ }_{3}^{3}$ Doutoranda pela Universidade Estadual do Norte Fluminense - Darcy Ribeiro, Campos dos Goytacazes - RJ, Avenida Alberto Lamego, 2000 - Parque Califórnia. CEP: 28013-602. E-mail: glauciamichelle2006@yahoo.com.br

${ }^{4}$ Professor pela Universidade Federal de São Carlos, Campus Sorocaba - SP, Rod. João Leme dos Santos, Km 110

Bairro do Itinga - CEP 18052-780. E-mail: walter@ufscar.br

${ }_{5}^{5}$ Professor pela Universidade Estadual do Norte Fluminense - Darcy Ribeiro, Campos dos Goytacazes - RJ, Avenida Alberto Lamego, 2000 - Parque Califórnia. CEP: 28013-602. E-mail: jugo@uenf.br
} 


\section{INTRODUÇÃO}

No ano de 2003, foi lançado no Brasil o primeiro mamão híbrido nacional - o UENF/ Caliman01 (UC01), produzido a partir da parceria entre a empresa Caliman Agrícola S/A e a Universidade Estadual do Norte Fluminense (UENF) (MARTINS; COSTA, 2003). Este híbrido apresenta características de qualidade bastante atraentes, como o teor de sólidos solúveis médio de $14^{\circ}$ Brix, polpa vermelha com ótimo aroma e peso médio dos frutos na faixa de $1.200 \mathrm{~g}$. No entanto o mesmo tem apresentado um amolecimento da polpa mais rápido que frutos dos outros dois genótipos mais cultivados no País, o híbrido Tainung01 e o 'Golden', o que compromete sua vida útil e dificulta seu transporte para mercados mais distantes.

O uso de solução à base de cálcio para minimizar a degradação da parede celular pode ser uma alternativa para a manutenção da firmeza do fruto (WERNER et al., 2009; RUIZ-MAY; ROSE, 2013). Este íon é um importante agente de estabilização das paredes celulares, atuando, também, na estabilização da membrana, bem como na sinalização celular (KITTERMANN et al., 2010; AGHDAM et al., 2012; NOMURA;SHIINA, 2014).

$\mathrm{O}$ ion cálcio também atua no fortalecimento da parede celular a partir da formação de ligações cruzadas carboxílicas entre ácidos pécticos e polissacarídeos (AGHDAM et al., 2012). A manutenção desse elemento no tecido diminui a atividade das enzimas pecto-hidrolíticas (CARDOSO et al., 2013), influenciando no grau de amaciamento da polpa do mamão e conferindo maior resistência ao manuseio (IRFAN et al., 2013). Sua participação nas ligações entre ácidos pécticos e polissacarídeos estabiliza a estrutura da parede e da membrana celular por meio da formação de uma rede de pectina envolvendo pontes de cálcio nos grupos carboxílicos não esterificados da estrutura poligalacturônica, o que dificulta o acesso das enzimas hidrolíticas, como a pectinametilesterase (WERNER et al., 2009) e irá influenciar na firmeza do fruto (MANGANARIS et al., 2007).

A aplicação do cálcio em pós-colheita tem demonstrado muitas vezes ser mais efetivo do que em pré-colheita, pois este é aplicado diretamente na superfície do fruto (KADIR, 2005), resultando em efeitos satisfatórios, principalmente no controle de doenças, porém sua viabilidade econômica ainda precisa de comprovação (IPPOLITO et al., 2005). Na aplicação em pós-colheita, são bastante utilizadas as técnicas de imersão dos frutos em solução de sais de cálcio, bem como o uso da imersão em soluções aquecidas ou, ainda, através da infiltração a vácuo. Esta última, consiste basicamente na penetração da solução contendo cálcio nos espaços intercelulares a partir da expulsão do ar dos espaços aéreos do tecido. Isso ocorre pelo efeito da capilaridade e pelo gradiente de pressão gerado pela saída do ar (VALERO; SERRANO, 2010; SILVEIRA et al., 2011). Dos diversos métodos de tratamentos do cálcio em frutos, a aplicação da solução de cloreto de cálcio a vácuo tem demonstrado resultados efetivos, incrementando o conteúdo de cálcio no tecido bem como prolongando a vida útil dos mesmos (SINGH et al., 2012; PADMANABAN et al., 2014). O incremento de cálcio no tecido pelo tratamento em pós-colheita tem reduzido desordens como o dano pelo frio - chilling, rachaduras na casca e escurecimento de polpa, mantendo o tempo de vida útil dos frutos conforme o observado em maçã (SAFTER et al.,1998), morango (HERNANDEZMUNOZ et al., 2008) e peras (MANGANARIS et al., 2007).

Conforme os resultados observados na literatura, o sistema de infiltração de cálcio a vácuo, pode ser uma alternativa à melhoria da qualidade $\mathrm{e}$ extensão da vida útil do mamão UC01, pois o mesmo apresenta perda de firmeza da polpa muito rápida. $\mathrm{O}$ presente estudo objetivou avaliar o efeito do tratamento com cálcio, na pós-colheita, de mamões UENF/Caliman01.

\section{MATERIAL E MÉTODOS}

Mamões UENF/Caliman01 no estádio 0 (fruto maduro fisiologicamente, entretanto com a casca $100 \%$ verde) foram colhidos no mês de novembro de 2013, em pomar comercial da Empresa Caliman Agrícola S.A., localizado no município de Linhares $\left(19^{\circ} 15^{\prime} \mathrm{S}, 39^{\circ} 51^{\prime} 70^{\prime \prime} \mathrm{W}\right)$, Espírito Santo, Brasil, e altitude de $30 \mathrm{~m}$. Os frutos foram transportados, sob refrigeração a $14^{\circ} \mathrm{C} \pm 1^{\circ} \mathrm{C}$, para a Universidade Estadual do Norte Fluminense "Darcy Ribeiro". Foram selecionados frutos que apresentavam maior uniformidade de tamanho, forma, peso, maturação e ausência de injúrias e doença.

Estes frutos foram separados em seis lotes contendo 18 frutos cada. Os frutos do lote- controle não receberam nenhum tipo de tratamento. Os outros lotes foram submetidos às concentrações de $0 \%, 2 \%$, $4 \%, 6 \%$ e $8 \% \mathrm{CaCl}_{2}(\mathrm{p} / \mathrm{v})$ por imersão e aplicação de vácuo, $50 \mathrm{kPa}$ por 3 minutos. No lote referente a $0 \%$, os frutos foram imersos em água, com aplicação do vácuo. Após serem tratados, os frutos foram secos, identificados, acondicionados em bandejas de 
poliestireno brancas e mantidos a $25^{\circ} \mathrm{C} \pm 1^{\circ} \mathrm{C}, 85 \% \pm$ $5 \%$ UR e déficit de pressão de vapor (DPV) do ar de $0,475 \mathrm{kPa}$. Eles foram avaliados a cada 3 dias após os tratamentos, durante os 12 dias de armazenamento, após a aplicação dos tratamentos (DAT), sendo que o tempo zero foi realizado após aplicação dos tratamentos e posterior secagem. A cada amostragem, os frutos foram avaliados quanto à perda de massa fresca (PMF), coloração da casca, firmeza do fruto com a casca (FF) e do mesocarpo (FM), teores de sólidos solúveis (SS), acidez titulável (AT), ácido ascórbico (AA) e de açúcares solúveis totais, assim como da relação SS/AT ("ratio").

A determinação da PMF foi obtida após a tomada do peso dos frutos no dia da aplicação do tratamento $(\mathrm{Pi})$ e no dia da avaliação $(\mathrm{Pf})$, a intervalos regulares de três dias $(0 ; 3 ; 6 ; 9$ e 12 dias), com os resultados expressos em porcentagem.

A cor da casca foi avaliada utilizando-se de colorímetro portátil (Chroma Meter, modelo CR-300, Minolta). Foram tomadas três leituras, em três locais equidistantes, na região equatorial do fruto, as quais compuseram um valor médio para o ângulo hue $\left(\mathrm{h}^{\circ}\right)$, que é um dos componentes de indicação da coloração do fruto. Foram realizadas três repetições, sendo cada repetição um fruto.

A firmeza do fruto (FF) e do mesocarpo (FM) foi medida como a força máxima de penetração para a ruptura do tecido e determinada usando-se uma ponta de prova de $8 \mathrm{~mm}$ x $8 \mathrm{~mm}$. Utilizou-se de penetrômetro digital de bancada, Fruit Pressure Tester (TR TURONI, modelo 53205, Italy). Foram tomadas quatro medições em pontos equidistantes, na região equatorial do fruto, sendo que, para a medida da firmeza do mesocarpo, foi feito um corte transversal na região equatorial e foram tomados pontos na região do mesocarpo. Os resultados foram expressos em Newton (N).

O teor de sólidos solúveis (SS) da polpa foi determinado a partir da extração de gotas de uma amostra da região mediana do mesocarpo, extraído por prensa manual e leitura direta em refratômetro digital ATAGO, modelo PR 201, com os resultados expressos em ${ }^{\circ}$ Brix. A acidez titulável (AT) foi determinada por titulometria com $\mathrm{NaOH}$ a $0,1 \mathrm{M}$, seguindo-se o método do Instituto Adolfo Lutz (1985), e os resultados, expressos em \% ácido cítrico. O "ratio" foi calculado usando-se a razão entre os teores de SS e AT (SS/AT) e usada como indicador de qualidade (CHITARRA; CHITARRA, 2005).

O teor de ácido ascórbico (AA) foi determinado por titulometria, seguindo-se o método descrito pela AOAC (2002), sendo os resultados expressos em mg AA. $100 \mathrm{~g}^{-1}$ massa fresca.
A determinação dos conteúdos de açúcares solúveis totais foi feita de acordo com o método descrito por Nelson-Somogyi (PADMAPRIYA, 2013).

A análise estatística dos resultados foi realizada através de análise de variância “oneway" (ANOVA). As médias foram comparadas, utilizando-se do teste de Tukey $(p<0,05)$. Os dados foram analisados graficamente com o intervalo de confiança (IC $p \leq 0,05$ ).

\section{RESULTADOS E DISCUSSÃO}

\section{Perda de massa fresca}

Todos os frutos mostraram perda de massa fresca progressiva durante o período de armazenamento (Figura 1). Os resultados mostraram que a PMF não foi significativamente influenciada $(p \leq 0,05)$ pela aplicação das soluções de $\mathrm{CaCl}_{2}$. Os frutos apresentaram PMF média de 5\% ao longo dos 12 dias de armazenamento, após a aplicação dos tratamentos (DAT) ou uma perda média de 5 g.dia ${ }^{-1}$. Diferentemente dos dados encontrados neste trabalho, Al-Eryani-Raqeeb et al. (2008) demostraram que a aplicação de cloreto de cálcio a vácuo na pós-colheita do mamão 'Eksotica II' reduziu significativamente a PMF dos frutos, que foi justificada pela maior dificuldade de saída de água quando as paredes e membranas celulares estão mais íntegras, o que é favorecido pelo cálcio. Segundo Hepler (2005), o cálcio tem um importante papel na função e na estrutura das membranas, uma vez que este se liga aos fosfolipídios estabilizando a bicamada lipídica e, assim, promovendo a integridade das membranas celulares. Isto também foi observado por Botelho et al. (2002) em goiabas 'Kumagai branca', tratadas com diferentes concentrações de $\mathrm{CaCl}_{2}$. Porém, Werner et al. (2009) observaram, em goiabas cv. Cortibel, incremento na perda de massa fresca à medida que aumentou a concentração do íon cálcio. De acordo com Azzolini et al. (2004), o excesso de sais de cálcio na solução aplicados sobre o fruto pode causar desidratação. Segundo Françoso et al. (2008), a perda de massa fresca é resultado do processo transpiratório somado aos mecanismos respiratórios via oxidação do carbono. A transpiração acarreta a perda de água e, quando ocorre de forma intensa, pode afetar diretamente a qualidade dos frutos, alterando sua aparência e, consequentemente, diminuindo sua aceitação. Entretanto, de acordo com Chitarra e Chitarra (2005), a perda de massa fresca, para ser considerada danosa e com redução na qualidade dos frutos, de modo geral, deve ser em torno de $10 \%$. 


\section{Cor da casca}

A cor da casca dos frutos é um dos principais atributos de qualidade e talvez o mais importante, devido a sua influência na escolha do produto por parte do consumidor. A variação da cor verde para amarela, que ocorre na casca do mamão, é uma das transformações físicas mais características, durante o amadurecimento do fruto (OLIVEIRA; VITÓRIA, 2011).

A cor da casca pode ser expressa pelo ângulo hue, cujos resultados indicam uma influência significativa pelos tratamentos (Figura 2). A diferença entre as médias dos tratamentos foi observada apenas no $6^{\circ}$ DAT, quando os frutos tratados com $6 \%$ de $\mathrm{CaCl}_{2}$ apresentaram os maiores valores do hue $\left(113,13^{\circ} \mathrm{h}\right)$. Observou-se, também, que durante o armazenamento, os valores do hue tenderam a diminuir ao longo dos dias, , o que reflete a perda de cor verde do fruto. Porém, a velocidade da mudança do verde para o amarelo foi menor nos frutos tratados com a solução de $6 \%$ de $\mathrm{CaCl}_{2}$, até o $6^{\circ} \mathrm{DAT}$. Nesse tratamento, a redução nos valores de hue foi de $10 \%$, enquanto no controle (frutos não tratados) ela foi de $25 \%$, quando se verificaram valores médios do hue de $91,89^{\circ} \mathrm{h}$, o que caracteriza um fruto amarelo.

Conforme o verificado por Souza et al. (2014), o pico climatérico no mamão UENF/Caliman01, armazenado em condição de ambiente $\left(25^{\circ} \mathrm{C} \pm 1^{\circ} \mathrm{e}\right.$ $85 \%$ UR), pode ter acontecido entre o $5^{\circ}$ e $6^{\circ}$ dias, o que pode explicar os menores valores de hue obtidos até o $6^{\circ}$ DAT para as amostras-controle e com baixas concentrações de $\mathrm{CaCl}_{2}$. A maior taxa de variação do ângulo hue no $6^{\circ} \mathrm{DAT}$ deve ser consequência da maior atividade metabólica associada ao aumento da respiração e da produção do etileno, durante o amadurecimento, quando são verificadas as mais intensas transformações qualitativas nos frutos (OLIVEIRA ; VITÓRIA, 2011).

A mudança na coloração da casca do mamão é uma consequência das mudanças no conteúdo dos pigmentos totais, como as clorofilas a e b e carotenoides, que são degradados e sintetizados, respectivamente, durante o processo de amadurecimento (JIMÉNEZ et al., 2014). O efeito da aplicação do $\mathrm{CaCl}_{2}$ na coloração da casca do mamão também foi verificado por Mahmud et al. (2008) e mostraram que o uso de infiltração de solução de $1,5 \% \mathrm{CaCl}_{2}$ a vácuo, em mamão 'Eksotika II', promoveu a manutenção do verde da casca, depois de 21 dias de armazenamento a $13^{\circ} \mathrm{C}$. Também se tem verificado que concentrações de $2 \%$ e $3 \% \mathrm{CaCl}_{2}$ foram eficientes na manutenção desta cor (SINGH et al., 2012).

\section{Firmeza}

A firmeza é um atributo de qualidade importante tanto para o manejo do produto, quanto para a aceitação pelo consumidor (CUQUEL et al., 2012). Os resultados verificados mostram que a FF e a FM foram significativamente influenciadas $(p \leq 0,05)$ pela aplicação de $\mathrm{CaCl}_{2}$ sob vácuo nos frutos intactos. A partir do $3^{\circ} \mathrm{DAT}$, a FF apresentou diferenças significativas $(p \leq 0,05)$ em função da aplicação dos tratamentos com efeito positivo das concentrações de $\mathrm{CaCl}_{2}$ na manutenção da $\mathrm{FF}$ (Figura 3A), pois os frutos tratados com as maiores concentrações de $\mathrm{CaCl}_{2}$ (6\% e $8 \%$ ) permaneceram firmes até o $6^{\circ}$ DAT. A taxa de perda de FF foi maior até o $6^{\circ}$ DAT para o controle e nos frutos tratados com $\mathrm{CaCl}_{2}$ a $2 \%$ e $4 \%$. Até o $6^{\circ} \mathrm{DAT}$, a taxa de redução da $\mathrm{FF}$ no controle e $0 \% \mathrm{CaCl}_{2}$ foi de $85 \%$, enquanto naqueles tratados com $\mathrm{CaCl}_{2}$, nas concentrações de $6 \%$ e $8 \%$, ela foi de $35 \%$. O período que vai até o $6^{\circ}$ DAT coincide com a maior mudança na cor da casca dos frutos, nestes mesmos tratamentos (Figura 2).

A firmeza do mesocarpo (FM) também foi significativamente influenciada $(p \leq 0,05)$ pela aplicação do $\mathrm{CaCl}_{2}$ após a colheita dos frutos, principalmente até o $3^{\circ} \mathrm{DAT}$, quando se verifica que o tratamento a $6 \% \mathrm{CaCl}_{2}$ apresentou frutos com maior FM, diferindo do controle e com $0 \% \mathrm{CaCl}_{2}$ (Figura 3B). Os frutos dos tratamentos-controle e $0 \% \mathrm{CaCl}_{2}$ apresentaram redução de $74 \%$, até o $3^{\circ}$ DAT, enquanto nos tratados com $6 \% \mathrm{CaCl}_{2}$ esta perda foi de $26 \%$, ou seja, uma diferença que caracteriza a melhor manutenção da resistência física do fruto. No $12^{\circ}$ DAT, não houve mais diferença entre os tratamentos, pois os frutos apresentavam firmeza com casca (FF) de $35 \mathrm{~N}$, em média, e do mesocarpo (FM), $5 \mathrm{~N}$, porém a redução na velocidade de perda da firmeza entre 0 DAT e $9^{\circ}$ DAT é de grande relevância para o transporte desta fruta, pois garante menores perdas por danos físicos.

A perda de firmeza trata de um processo natural do desenvolvimento de diversos frutos. O mamão, devido ao aumento da atividade de enzimas que atuam na degradação da pectina, presente nas paredes celulares, tem essa atividade aumentada à medida que os frutos amadurecem (ALBERSHEIM et al., 2011; GAYATHRI; NAIR, 2013). O transporte dos frutos, do local de colheita até o de armazenamento, quando ocorre de forma inapropriada, aumenta esse amolecimento e, consequentemente, a perda dos mesmos, contribuindo para aumentar as perdas na pós-colheita (MORAIS et al., 2010).

Trabalhos encontrados na literatura, assim como os resultados observados neste trabalho, indicam que o tratamento com cálcio na pós-colheita 
tem sido efetivo em retardar a perda de firmeza em frutos climatéricos, como o mamão (AL-ERYANIRAQEEB, 2008; ALEXANDRO DE MORAIS et al., 2010), a maçã (HUSSAIN et al., 2012), a goiaba (WERNER et al., 2009) e o figo (IRFAN et al., 2013), ou em frutos não climatéricos, como o morango (CHEN et al., 2011).O efeito do cálcio na manutenção da FM também é relatado em trabalhos de processamento mínimo como em banana (VILAS BOAS et al., 2009) e goiaba (INAM-UR-RAHEEM et al., 2013), com aumento significativo na vida útil desses produtos.

\section{Sólidos solúveis}

O teor de SS não foi influenciado $(p \leq 0,05)$ pela infiltração a vácuo das soluções de $\mathrm{CaCl}_{2}$, como também não variou durante o amadurecimento do mamão (Figura 4A), pois em mamão este teor varia muito pouco durante o amadurecimento (ALI et al., 2014). Por ser um fruto que apresenta quantidadestraço de amido na polpa, a variação no teor de SS após a colheita é muito pequena e, quando ocorre, é resultado da degradação da parede celular, que aumenta a liberação de pectina solúvel nos espaços intercelulares, contribuindo com um ligeiro aumento no teor de SS (YAO et al., 2014). Apesar de a infiltração de $\mathrm{CaCl}_{2}$ nos frutos ter resultado em manutenção da FF e FM por mais tempo que o observado para os frutos do controle (Figuras $3 \mathrm{~A}$ e $3 \mathrm{~B}$ ), a partir do $9^{\circ} \mathrm{DAT}$, essas apresentavam valores iguais ao dos frutos do controle, sem contudo provocar aumento no teor de SS. Isto indica que a perda de FF e FM no mamão influencia muito pouco no teor de SS da polpa (CHAN et al., 1979; PAULL, 1993; SOUZA et al., 2009a).

O fato de o mamão não apresentar variações no teor de SS durante sua pós-colheita (YAO et al., 2014), indica que esse atributo pode não ser adequado para diferenciar o efeito da infiltração de soluções de $\mathrm{CaCl}_{2}$ na pós-colheita do mamão, como o indicado por Valero e Serrano (2010).

\section{Acidez Titulável}

AAT da polpa dos mamões não foi influenciada pela aplicação do $\mathrm{CaCl}_{2}$ na pós-colheita (Figura 4B). Os resultados indicam uma tendência similar à verificada para o teor de $\mathrm{SS}$, com exceção dos dados do início da avaliação, quando foi verificada diferença significativa $(p \leq 0,05)$ entre os tratamentos, atribuída à heterogeneidade das amostras quanto ao conteúdo dos ácidos orgânicos. Os valores relatados para a AT dos mamões estão em concordância com os valores encontrados por Al-Eryani Raqeeb et al. (2008) e Simões et al. (2013).
O efeito do tratamento com cálcio na AT tem sido apresentado na literatura com resultados bastante variáveis. Figueroa et al. (2012) verificaram que o uso de $\mathrm{CaCl}_{2}$ em morango (Fragaria chiloensis) não resultou em mudanças significativas na AT, entretanto o conteúdo de ácidos urônicos solúveis em água foi menor nos frutos tratados com $\mathrm{CaCl}_{2}$. Por outro lado, Mahmud et al. (2008) observaram que a quantidade de ácidos orgânicos disponíveis no extrato da polpa de goiaba 'Paluma' e de mamão 'Eksotika II' diminuiu em função do aumento na concentração da solução de cálcio aplicada. Segundo esses autores, isso se deve à redução da respiração, o que implicaria atraso no processo de amadurecimento dos frutos tratados.

\section{Razão SS/AT}

A razão SS/AT é uma importante variável de qualidade na pós-colheita dos frutos, pois a mesma expressa o equilíbrio entre a doçura e a acidez, representando, em parte, a sensação experimentada no paladar do consumidor (DIAS et al., 2011). A razão $\mathrm{SS} / \mathrm{AT}$ foi significativamente influenciada $(p \leq 0,05)$ pelos tratamentos com $\mathrm{CaCl}_{2}$ apenas no $9^{\circ}$ DAT, quando os frutos-controle e $0 \% \mathrm{CaCl}_{2}$ apresentaram valores médios $(135,50)$ superiores aos verificados $(114,32)$ nos frutos tratados com $6 \% \mathrm{CaCl}_{2}$ (Figura 4C). Os resultados verificados foram maiores que os encontrados por Fontes et al. (2012) em mamão UENF/Caliman01, 78,5, contudo menores que os relatados por Souza et al. (2009b), que registraram valores médios de 203,11 a 249,87, em mamões Tainung01.

\section{Ácido ascórbico}

O teor de AA na polpa do mamão UENF/ Caliman01, de modo geral, apresentou incremento significativo $(p \leq 0,05)$ ao longo do período de armazenamento, pois no 0 DAT os teores iniciais, em média, eram de $36,86 \mathrm{mg} .100 \mathrm{~g}^{-1} \mathrm{MF}$, enquanto no último dia de análise estes valores aumentaram para $69,04 \mathrm{mg} .100 \mathrm{~g}^{-1}$, porém sem diferenças significativas entre os tratamentos (Figura 4D). No $6^{\circ}$ DAT e no $9^{\circ}$ DAT, houve redução significativa nos teores de ácido ascórbico dos frutos tratados com 6\% e 8\% de $\mathrm{CaCl}_{2}$, em relação aos frutos- controle e $0 \% \mathrm{CaCl}_{2}$. A diminuição na síntese de AA para os frutos com maiores concentrações de $\mathrm{CaCl}_{2}$ pode ser justificada pela menor atividade respiratória destes frutos, dado o menor fornecimento de 'substrato' respiratório pela menor atividade de enzimas pectinolíticas (MAHMUD et al., 2008). Uma consequência deste fenômeno é o menor fornecimento de intermediários pela oxidação de açúcares que levariam à produção 
de L-galactona-1,4-lactona (GL), precursor imediato na via de síntese do AA, a partir da ação da enzima L-galactona-1,4-lactona desidrogenase (GLDH) (SMIRNOFF ; WHEELER, 2000).

No entanto, goiabas 'Cortibel', quando tratadas em pós-colheita com $\mathrm{CaCl}_{2}$, apresentaram menor diminuição nos teores de AA quando comparadas aos frutos não tratados, justificado pela possível redução na degradação de polissacarídeos da parede celular e relacionados à via de síntese de AA em plantas (WERNER et al., 2009; SZARKA et al., 2013). Resultados semelhantes também foram observados por Torres et al. (2010) em atemoia (Annona cherimola Mill x Annona squamosa L.), e também em figo (Ficus carica L.) por Irfan et al. (2013). Porém, em maçã e tomates tratados com cloreto de cálcio, o conteúdo de vitamina $\mathrm{C}$ aumentou (BANGERTH, 1976).

\section{Açúcares solúveis totais}

A porcentagem total de açúcares solúveis é de grande importância para determinar a qualidade dos frutos, haja vista que o sabor dos mesmos depende deste conteúdo (MUJTABA; MASUD, 2014). A Figura 5 indica que, durante o armazenamento, houve poucas variações na porcentagem desses açúcares na massa fresca do mamão UENF/Caliman01, sem efeito significativo $(p \leq 0,05)$. Entretanto, os teores de açúcares solúveis totais foram significativamente influenciados $(p \leq 0,05)$ pela aplicação das soluções de $\mathrm{CaCl}_{2}$.

Os frutos não tratados (controle) apresentaram ligeira diminuição no teor de açúcares solúveis totais, variando de $11,3 \%$ para $10,22 \%$ ao longo do armazenamento. Estes valores são menores que os encontrados por Othman (2009), que registrou teor de açúcares solúveis totais de $15 \%$ em mamões, realizado no leste da Tanzânia, e também verificou aumento nos teores de açúcares solúveis totais durante o armazenamento a $25^{\circ} \mathrm{C}$, o que não foi o observado neste trabalho. Zamam et al. (2006) também verificaram incremento nos teores de açúcares solúveis totais em mamões indianos. Em tomate, os frutos, quando tratados com $\mathrm{CaCl}_{2}$, apresentaram incremento dos açúcares totais ao longo do armazenamento, porém, assim como observado neste trabalho, houve redução à medida que se aumentaram as concentrações de $\mathrm{CaCl}_{2}$, justificado pela menor taxa respiratória e maior estabilização das ligações pécticas promovidas pelo cálcio.

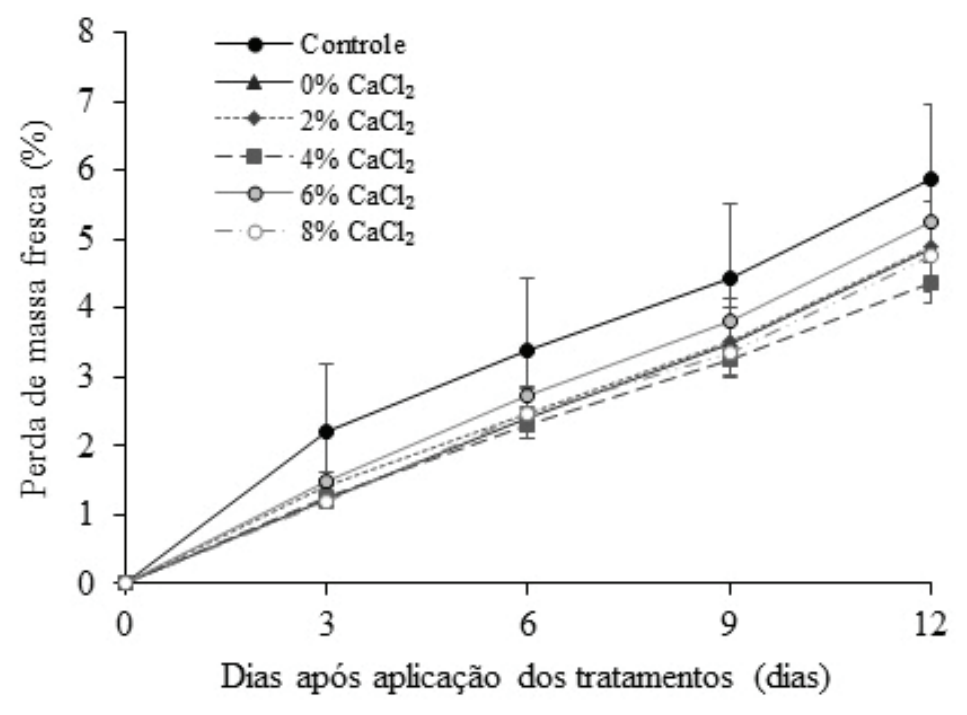

FIGURA 1 - Perda de massa fresca por mamões UENF/Caliman01 submetidos a diferentes tratamentos com $\mathrm{CaCl}_{2}$ e armazenados a $25^{\circ} \mathrm{C}$ e $85 \%$ UR (IC, $\left.p \leq 0,05\right)$. 


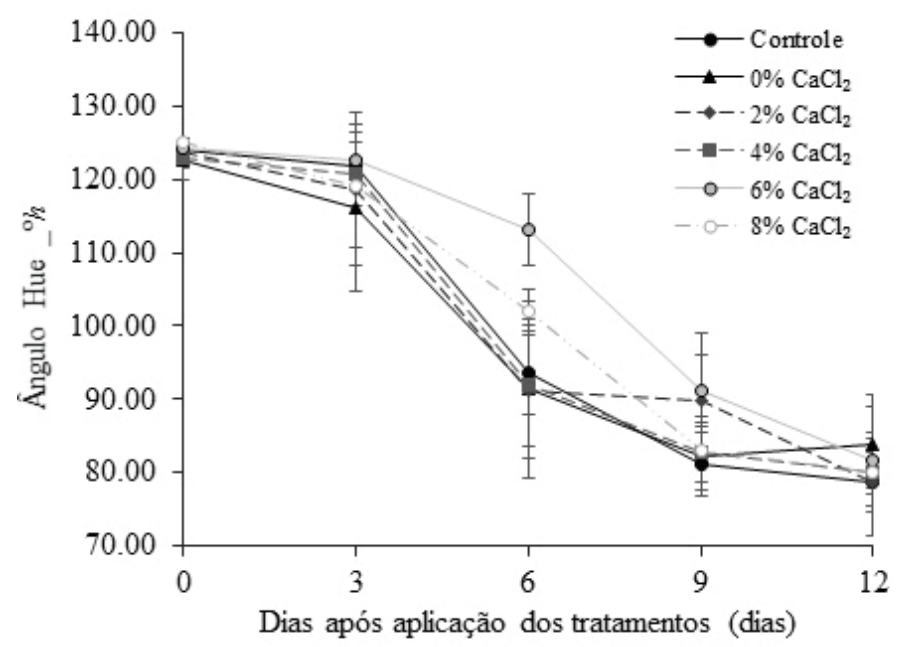

FIGURA 2 - Ângulo hue em mamões UENF/Caliman01 submetidos a diferentes tratamentos com $\mathrm{CaCl}_{2} \mathrm{e}$ armazenados a $25^{\circ} \mathrm{C}$ e $85 \%$ UR (IC, $\left.p \leq 0,05\right)$.
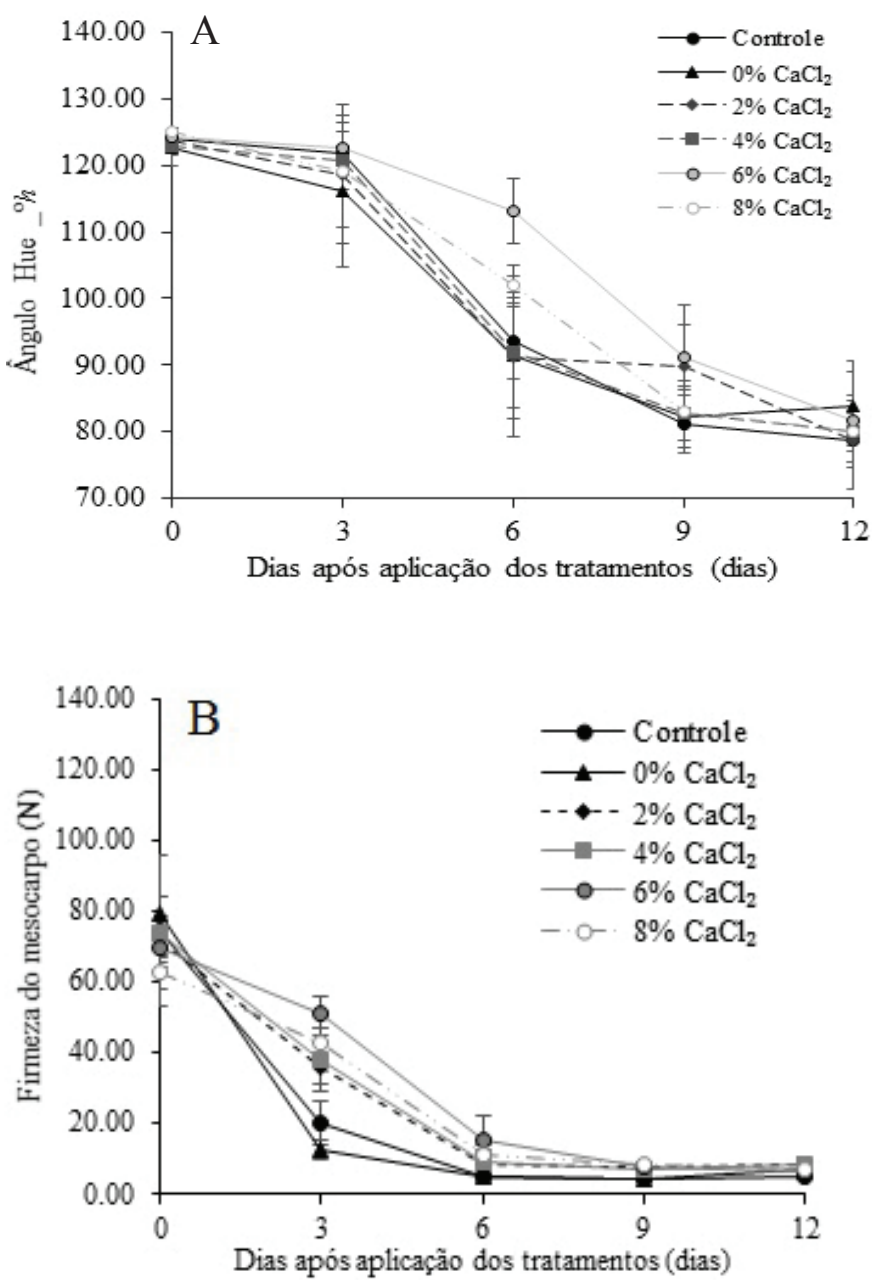

FIGURA 3 - Firmeza do fruto (A) e do mesocarpo (B) em mamões UENF/Caliman01 submetidos a diferentes tratamentos com $\mathrm{CaCl}_{2}$ e armazenados a $25^{\circ} \mathrm{C}$ e $85 \%$ UR (IC, $p \leq 0,05$ ). 

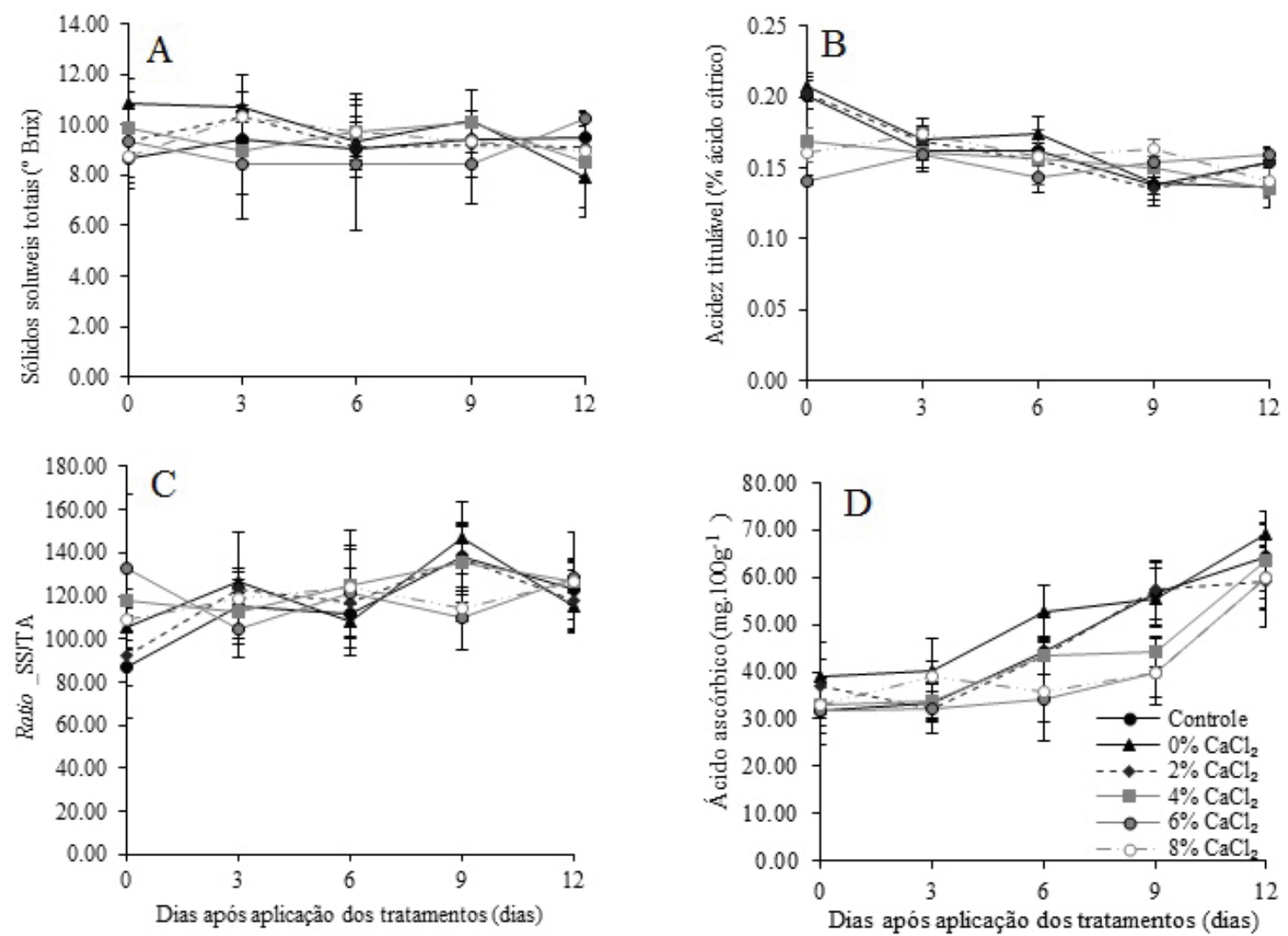

FIGURA 4 - Mudanças nas características químicas, sólidos solúveis (A), acidez titulável (B), razão SS/ AT (C) e ácido ascórbico (D) na polpa de mamões UENF/Caliman01 submetidos a diferentes tratamentos com $\mathrm{CaCl}_{2}$ e armazenados a $25^{\circ} \mathrm{C}$ e $85 \%$ UR (IC, $p \leq 0,05$ ).

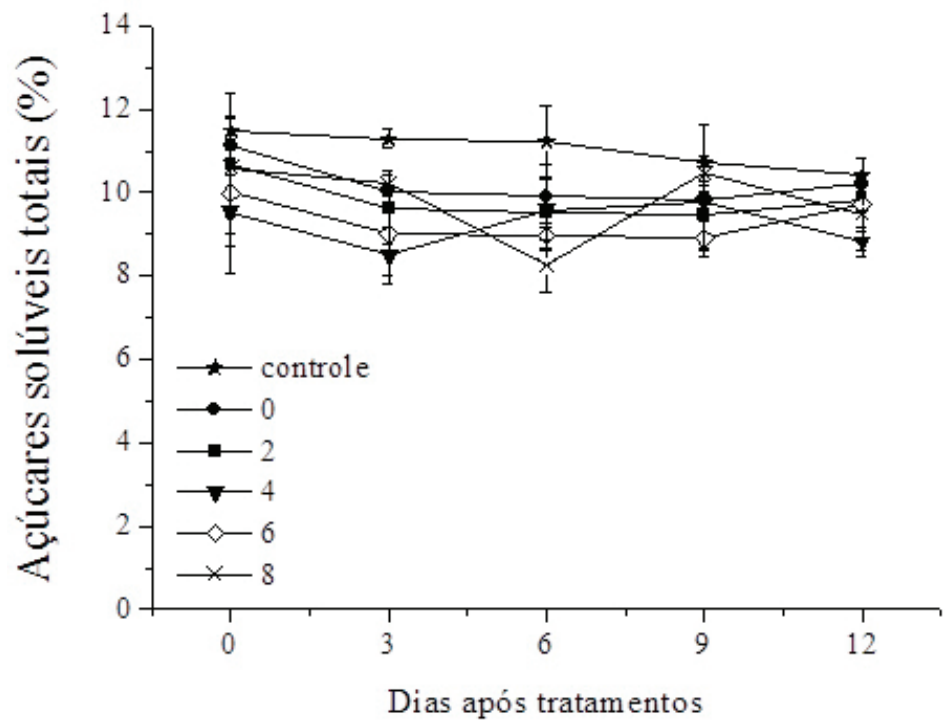

FIGURA 5 - Mudanças nos teores de açúcares solúveis totais na polpa de mamões UENF/Caliman01 submetidos a diferentes tratamentos com $\mathrm{CaCl}_{2}$ e armazenados a $25^{\circ} \mathrm{C}$ e $85 \% \mathrm{UR}(\mathrm{IC}, p \leq 0,05)$. 


\section{CONCLUSÕES}

A infiltração do mamão UENF/Caliman01, com soluções com $6 \%$ e $8 \%$ de $\mathrm{CaCl}_{2}$, na póscolheita, foi capaz de influenciar na qualidade do mesmo, melhorando alguns aspectos, como a manutenção da firmeza do fruto e do mesocarpo e retardando a mudança de cor da casca, o que pode favorecer a comercialização dos mesmos em mercados mais distantes.

Este tratamento com $\mathrm{CaCl}_{2}$ não diminuiu a perda de massa fresca pelos frutos bem como não interferiu nos teores de sólidos solúveis e acidez titulável, e na relação SS/AT. Ele diminuiu a síntese de ácido ascórbico, bem como a de açúcares solúveis totais.

\section{AGRADECIMENTOS}

Ao CNPq e à FAPERJ, pelas bolsas de estudo, de pesquisa e auxílio financeiro, e à Caliman Agricola S. A., pelo fornecimento dos frutos.

\section{REFERENCIAS}

AGHDAM, M.S.; HASSANPOURAGHDAM, M.B.; PALIYATH, G.; FARMANI, B. The language of calcium in postharvest life of fruits, vegetables and flowers. Scientia Horticulturae, Amsterdam, v.144, p.102-115, 2012.

ALBERSHEIM, P.; DARVILL, A.; ROBERTS, K.; SEDEROFF, R.; STAEHELIN, A. Plant Cell Walls. New York: Garland Science, 2011. p.430-433.

AL-ERYANI-RAQEEB, A.; MAHMUD, T.M.M.; SYED OMAR, S.R.; MOHAMED ZAKI, A.R.; AL-ERYANI, A.R. Effects of calcium and chitosan treatments on controlling anthracnose and postharvest quality of papaya (Carica papaya L.). International Journal of Agricultural Research, New York, v.4, n.2, p.53-68, 2008.

ALI, A.; ONG, M.K.; FORNEY, C.F. Effect of ozone pre-conditioning on quality and antioxidant capacity of papaya fruit during ambient storage. Food Chemistry, Washington, v.142, p.19-26, 2014.

AOAC - Association of Official Analytical Chemists. Official methods of analysis of the Association of Official Analytical Chemists. $17^{\text {th }}$ ed. Washington, 2002. 1115p.
BANGERTH, F. Relationship between calcium content and the content of ascorbic acid in apple, pear and tomato fruits. Quality Plant, Coimbra, v.26, p.341-348, 1976.

BOTELHO, R. V.; SOUZA, N.L.; PERES, N. A. R. Qualidade pós-colheita de goiabas 'Branca de Kumagai' tratadas com cloreto de cálcio. Revista Brasileira de Fruticultura, Jaboticabal, v.24, n.1, p.063-067, 2002.

CARDOSO, L.; DEUS, V.; SILVA, E.; ANDRADE JÚNIOR, V. C.; DESSIMONI-PINTO, N. V. Qualidade pós-colheita de morangos cv. Diamante tratados com cloreto de cálcio associado a hipoclorito de sódio. Alimentos e Nutrição, Araraquara, v.23, n.4, p.588, 2013.

CHAN JR, H.T.; HIBBARD, K.; GOO, T.; AKAMINE, E. K. Sugar composition of papayas during fruit development. HortScience, St Joseph, v. 14 , n. 2, p. 140-141, 1979.

CHEN, F.; LIU, H.;YANG, H.; LAI, S.; CHENG, X.; XIN, Y.; DENG, Y. Quality attributes and cell wall properties of strawberries (Fragaria annanassa Duch.) under calcium chloride treatment. Food Chemistry, Washington, v.126, n.2, p.450-459, 2011.

CHITARRA, M.I.F.; CHITARRA, A.B. Pós-colheita de frutas e hortaliças: fisiologia e manuseio. 2. ed. Lavras: FAEPE, 2005. p.785

CUQUEL, F. L.; OLIVEIRA, C. F. S.; LAVORANTI, O. J. Sensory profile of eleven peach cultivars. Ciência e Tecnologia de Alimentos, Campinas, v.32, n.1, p.70-75, 2012.

DIAS, T.C.; MOTA, W.F.; OTONI, B.S.; MIZOBUTSI, G.P.; SANTOS, M.G.P. Conservação pós-colheita de mamão formosa com filme de PVC e refrigeração. Revista Brasileira de Fruticultura, Jaboticabal, v.33, n.2, p.666-670, 2011.

FIGUEROA, C.R.; OPAZO, M.C.; VERA, P.; ARRIAGADA, O.; DÍAZ, M.; MOYA-LEÓN, M.A. Effect of postharvest treatment of calcium and auxin on cell wall composition and expression of cell wallmodifying genes in the Chilean strawberry (Fragaria chiloensis) fruit. Food Chemistry, Washington, v.132, n.4, p.2014-2022, 2012. 
FONTES, R. V.; VIANA, A. P.; PEREIRA, M. G.; OLIVEIRA, J. G.; VIEIRA, H. D. Manejo da cultura do híbrido de mamoeiro (Carica papaya L.) do grupo 'formosa' UENF/CALIMAN - 01 para melhoria na qualidade do fruto com menor aplicação de adubação NPK. Revista Brasileira de Fruticultura, Jaboticabal, v.34, n.1, p.143-151, 2012.

FRANÇOSO, I.L.T.; COUTO, M.A.L.; CANNIATTIBRAZACA, S.G.; ARTHUR, V. Alterações físicoquímicas em morangos (Fragaria anassa Duch.) irradiados e armazenados. Ciência e Tecnologia de Alimentos, Campinas, v.28, n.3, p.614-619, 2008.

GAYATHRI, T.; NAIR, A.S. Isolation, purification and characterisation of polygalacturonase from ripened banana (Musa acuminata cv. Kadali). International Journal of Food Science and Technology, Oxford, v.1, p.1-6, 2013.

HEPLER, P.K. Calcium: a central regulator of plant growth and development. The Plant Cell, Vermont, v. 17, p.2142-2155, 2005.

HERNANDEZ-MUNOZ, P.; ALMENAR, E.; DEL VALLE, V.; VELEZ, D.; GAVARA, R. Effect of chitosan coating combined with postharvest calcium treatment on strawberry (Fragaria x ananassa) quality during refrigerated storage. Food Chemistry, Washington, v.110, p.428-435, 2008.

HUSSAIN, P.R.; MEENA, R.S., DAR, M.A., WANI, A.M. Effect of post-harvest calcium chloride dip treatment and gamma irradiation on storage quality and shelf-life extension of Red delicious apple. Journal of Food Science and Technology, Oxford, v.49, n.4, p.415-426, 2012.

INAM-UR-RAHEEM, M.; HUMA, N.; ANJUM, F.M.; MALIK, A.U. Effect of calcium chloride and calcium lactate on quality and shelf-life of freshcut guava slices. Pakistan Journal Agricultural Science, Faisalabad, v.50, n.3, p. 427-431, 2013.

INSTITUTO ADOLFO LUTZ. Normas analíticas, métodos químicos e físicos de alimentos. 3.ed. São Paulo: IAL, 1985. v. 1, p.553-560.
IPPOLITO, A.; SCHENA, L.; PENTIMONE, I.; NIGRO, F. Control of postharvest rots of sweet cherries by pre- and postharvest applications of Aureobasidium pullulansin combination with calcium chloride or sodium bicarbonate. Postharvest Biology and Technology, Amsterdam, v.36, n.3, p.245-252, 2005.

IRFAN, P.K.; VANJAKSHI, V.; PRAKASH, M.N.; RAVI, R.; KUDACHIKAR, V.B. Calcium chloride extends the keeping quality of fig fruit (Ficus carica L.) during storage and shelf-life. Postharvest Biology and Technology, Amsterdam, v.82, p.7075, 2013.

JIMÉNEZ, V.M.; MORA-NEWCOMER, E.; GUTIÉRREZ-SOTO, M.V. Biology of the papaya plant. In: MING R.; MOORE, P.H. (Ed.). Genetics and genomics of papaya, plant genetics and genomics: crops and models 10. New York: Springer Science-Business Media, 2014. p. 17-33.

KADIR, S.A. Fruit quality at harvest of 'Jonathan' apple treated with foliarly - applied calcium chloride. Journal of Plant Nutrition, Oxon, v.27, n.11, p.1991-2006, 2005.

KITTERMANN, D.; NEUWALD, D.A.; STREIF, J. Influence of calcium on fruit firmness and cell wall degrading enzyme activity in 'Elstar' apples during storage. Acta Horticulturae, The Hague, n.877, p.1037-1043, 2010.

MAHMUD, T.M.M.; ERYANI-RAQEEB, A.; SYED OMAR, S.R.; MOHAMED ZAKI, A.R.; ERYANI, A. Effects of different concentrations and applications of calcium on storage life and physicochemical characteristics of papaya (Carica Papaya L.). American Journal of Agricultural \& Biological Science, New York, v.3, p.526-533, 2008.

MANGANARIS, G.A.; VASILAKAKIS, M.; DIAMANTIDIS, G.; MIGNANI, I. The effect of postharvest calcium application on tissue calcium concentration, quality attributes, incidence of flesh browning and cell wall physicochemical aspects of peach fruits. Food Chemistry, Washington, v.100, n.4, p.1385-1392, 2007.

MARTINS, D.S.; COSTA, A.F.S. A cultura do mamoeiro: tecnologias de produção. Vitória: Incaper, 2003. p. 497. 
MORAIS, F.A. de; ARAÚJO, F.M.M. C. de; MACHADO, A.V.; RICARTE, F.D.N.; SALES JUNIOR, R. Influência da atmosfera modificada sob a vida útil pós-colheita do mamão 'Formosa'. Revista Verde de Agroecologia e Desenvolvimento Sustentável, Pombal, v.5, n.4, p.01-09, 2010.

MUJTABA, A., MASUD, T. Enhancing post harvest storage life of tomato (Lycopersicon esculentum Mill.) cv. Rio Grandi using calcium chloride, American-Eurasian Journal Agricultural \& Environment Scientia, Deira, v.14, n.2, p.143-149, 2014.

NOMURA, H.; SHIINA, T. Calcium signaling in plant endosymbiotic organelles: mechanism and role in physiology. Molecular Plant, Oxford, v.20, p.1094-1104, 2014.

OLIVEIRA, J.G.; VITORIA, A.P. Papaya: nutritional and pharmacological characterization, and quality loss due to physiological disorders. An overview. Food Research International, Amsterdam, v.44, n.5, p.1306-1313, 2011.

OTHMAN, O. C. Physical and chemical composition of storage-ripened papaya (Carica papaya L.) fruits of Eastern Tanzania. Tanzania Journal of Science, Dar es Salaam, v.35, n.1, p.47-55, 2009.

PADMANABAN, G., SINGARAVELU, K., ANNAVI, S.T. Increasing the shelf-life of papaya through vacuum packing. Journal of Food Science and Technology, Oxford, v.51, n.11, p. 163-167, 2014.

PADMAPRIYA, T. Nutritient content of the papaya powder obtained by different methods of drying. International Journal of Scientific Research, Gujarat, v.2, n.5, p.1-2, 2013.

PAULL, R.E. Pineapple and papaya. In: SEYMOUR, G.B.; TAYLOR, J.E.; TUCKER, G.A. Biochemistry of fruit ripening. Netherlands: Springer, 1993. p. 302-315.

RUIZ-MAY, E.; ROSE, J.K.; Cell wall architecture and metabolismo in ripening fruit and the complex relationship with softening. In: SEYMOUR, G.; TUCKER, G.A.; POOLE, M.; GIOVANNONI, J.J.; TUCKER, A.G. The molecular biology and biochemistry of fruit ripening. New Delhi: Black Well, 2013. p.163-165.
SAFTER, R.A.; CONWAY, W.S., SAMS, C.E. Effects of postharvest calcium and fruit coating treatments on postharvest life, quality maintenance, and fruit surface injury in 'Golden Delicious' apples. Journal of the American Society for Horticultural Science, Alexandria, v.123, p.294-298, 1998.

SILVEIRA, A.C.; AGUAYOB, E.; CHISARIC, M.; ARTÉSB, F. Calcium salts and heat treatment for quality retention of fresh-cut 'Galia' melon. Postharvest Biology and Technology, Washington, v.62, p.77-84, 2011.

SIMÕES, E.B.; SANTOS, A.C.; LUCAS, M.R. Caracterização da qualidade instrumental e sensorial de papaia 'Solo' e 'Local' produzido em Santiago, Cabo Verde, e análise crítica sobre a importação da papaya. Évora: Repositório Universidade de Évora, 2013. p.1-21. Disponível

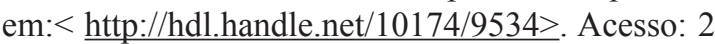
abr. 2014.

SINGH, P.; KUMAR, S.; MAJI, S.; KUMAR, A. YADAV, Y.C. Effect of calcium chloride on postharvest changes in papaya fruits. Asian Journal of Horticulture, Ghaziabad, v.7, n.1, p113-117, 2012.

SMIRNOFF, N.; WHEELER, G.L. Ascorbic acid in plants: biosynthesis and funcion. Critical Reviews in Biochemistry and Molecular Biology,New York, v.35, n.4, p.291-314, 2000.

SOUZA, A.F.; SILVA, W.B.;GOMES, M.; SOUZA, Y.G.; OLIVEIRA, J.G. Fisiologia do amadurecimento do mamão. Estudo comparativo sob condições de prateleira entre as principais variedades comercializadas no Brasil. Revista Brasileira de Fruticultura, Jaboticabal, v.36 n.1 p.29-36, 2014.

SOUZA, M.S.D.; OLIVEIRA, J.; AZEVEDO, I.; CORRÊA, S.; SILVA, M.; PEREIRA, M. Resposta da aplicação do 1-MCP em frutos de mamoeiro 'Golden' em diferentes estádios de maturação. Revista Brasileira de Fruticultura, Jaboticabal, v.31, n.3, 693-700, 2009a.

SOUZA, T.V.; COELHO, E.F.; PAZ, V.P.S.; LEDO, C.A.S. Avaliação física e química de frutos de mamoeiro 'Tainung $n^{\circ} 1$ ', fertirrigado com diferentes combinações de fontes nitrogenadas. Agrária, Recife, v.4, n.2, p.179-184, 2009 b. 
SZARKA, A.; BÁNHEGYI, G.; ASARD, H. The inter-relationship of ascorbate transport, metabolism and mitochondrial, plastidic respiration. Antioxidants \& Redox Signaling. New Rochelle, v.19, p.1036-1044, 2013.

TORRES, L.M.A.R.; SILVA, M.D.; GUAGLIANONI, D.G.; NEVES, V.A. Effects of heat treatment and calcium on postharvest storage of atemoya fruits. Alimentos e Nutrição, Araraquara, v.20, n.3, p.359$368,2010$.

VALERO, D.; SERRANO, M. Calcium treatments In: VALERO, D.; SERRANO, M. Postharvest biology and technology for preserving fruit quality. New York: CRS, 2010. v.1, cap. 6, p.109.

VILAS BOAS, E.V.B.; REIS, C.M.F.; MELO,A.A.M. Uso de misturas químicas para a manutenção da firmeza de banana 'prata' minimamente processada. Ciência e Agrotecnologia, Lavras, v.33, n.1, p.237244, 2009.
WERNER, E.T.; JUNIOR-OLIVEIRA, L.F.G.D.; BONA, A.P.D.; CAVATI, B.; GOMES, T.D.U.H. Efeito do cloreto de cálcio na pós-colheita de goiaba 'Cortibel'. Bragantia, Campinas, v.68, n.2, p.511518, 2009.

YAO, B.N.; TANO, K.; KONAN, H.K.; BÉDIÉ, G.K.; OULÉ, M.K.;KOFFI-NEVRY, R.; ARUL, J. The role of hydrolases in the loss of firmness and of the changes in sugar content during the postharvest maturation of Carica papaya L. Journal of Food Science and Technology, Oxford, v.51, n.11, p.3309-3316, 2014.

ZAMAM, W.; BISWAS, S.K.; HELALI, M.O.H.; IBRAHIM, M.; HASSAN, P. Physicochemical composition of four papaya varieties grown at Rajshahi. Journal of Biosciences, Heidelberg, v.14, p.83-86, 2006. 